The Geneva Papers on Risk and Insurance, 20 (No. 76, July 1995) 393-401

\title{
Reinsurance of Environmental Risk Pricing and Risk Assessment*
}

\author{
by Reiner Bellenbaum**
}

\begin{abstract}
Summary
Despite the increasing liberalisation of insurance markets, the principle of the locality of an insurance business remains decisive for General Liability business and particularly for the insurance of environmental impairment liability. General Liability insurance has its basis in national legislation and there is no need to describe how much this legislation differs with respect to environmental liability between the European countries.
\end{abstract}

\section{Legal framework for environmental liability in Germany}

Before discussing the German insurance model and the insurability of environmental risks, therefore, we must first take a look at the existing legal framework in Germany.

\subsection{The Environmental Liability Act (UHG)}

The Environmental Liability Act has been in force in Germany since 1st January 1991. The Act is based on the premise that the operators of such facilities as are listed in Appendice 1 and 2 to the Act are strictly liable for any environmental impairment caused by these facilities. The liability also includes damage arising out of normal operation: this means it is no defence for an operator to claim that the authorities had granted him a licence for the emission in question.

Nor is a defence based on "state of the art" possible. This implies that operators must expect to be held liable for environmental impacts which are later discovered as being dangerous.

For the facilities listed in Appendix 2 to the Act - especially those for which safety analyses are required by law, for example power plants and waste-disposal plants - the Act prescribes the operator's obligation to take precautions to pay losses. This obligation can be discharged, for example, by tendering proof of having taken out third-party liability insurance for the facility in question. But the relevant regulations for this compulsory cover mentioned in Article 19 of the Act have not yet been enacted.

* Paper presented at the MORE 10 - Seminar in Paris, November 1994.

** Stv Direktor, Leiter HUK Fakultativ und Service, Bayerische Rückversicherung Aktiengesellschaft, Munich. 
Working against the operator of a facility is the principle of the "assumed causal link", which can be refuted only if the operator can prove that the facility had been operated in accordance with the relevant regulations. However, operation of a facility in accordance with its intended purpose is only vaguely described as "the observance of the obligations of operation".

The Act limits liability per loss to DM 160 million for both bodily injury and property damage.

\subsection{The Water Resources Management Act (WHG), Article 22}

Apart from, the UHG the Water Resources Management Act (WHG) remains unchanged and in force. This Act regulates liability for pollution of waterbodies and/or damage resulting from the pollution of groundwater, irrespective of fault. According to Article 20 of the Act, an operator of a facility may be held liable if substances which are dangerous to water escape from the facility and enter a waterbody and/or the groundwater. The same applies if the operator deliberately introduces such substances - with or without authorisation - into a waterbody, thus causing damage to a third party.

\subsection{The Federal Immission Prevention Act (BImSchG), Article 14}

This act is a statutory standard which sets down permissible or tolerable immission limits. However; the Act refers only to directly adjoining properties.

\subsection{German Civil Code (BGB), Articles 823, 906}

The provisions of the general law of obligations also apply to environmental liability, with it having to be proven that the defendant was at fault. Here, too, the courts have begun to reverse the burden of proof (e.g. the Kupolofen judgement). If the damaged party can show conclusively that the damage must have been caused by the defendant's facility, the onus is then on the defendant to prove his innocence.

This reversal of the burden of proof came about because it is generally impossible for a plaintiff to gain knowledge of the internal operation of an industrial plant.

\subsection{General regulations}

General regulations allow the authorities in most of the German states to demand that the owners of anything constituting a threat to the general public eliminate that threat. If the owner fails to do so, the authority is empowered to carry out elimination itself at the owner's expense.

This provision is often used in combination with Article 22 of the Water Resources Management Act to clean-up ground pollution before the groundwater is polluted. For cases of this kind alone, German primary insurers have paid or reserved more than DM 1.8 billion in recent years.

\section{Environmental Impairment Liability insurance (UHV)}

Environment Impairment Liability (UHV) insurance is based on the General Conditions of Liability Insurance (AHB). These conditions govern the insurance of statutory claims for damages under private law. Should legislation change, any extension of liability is considered to be covered by the conditions of insurance. 
Until the General Conditions of Insurance were amended in 1993, the environmental liability risk was not explicitly mentioned in them and was thus considered to be covered without restriction. This applied to bodily injury, whereas gradual damage to property was excluded under Article 4.1.5. AHB. In individual cases, however, this exclusion was dropped from certain industrial policies. Pure financial loss is generally excluded from cover.

Since the introduction of the WHG liability policy in 1957 there has been separate cover for claims for damages arising out of the pollution of waterbodies including groundwater. This insurance offers cover for bodily injury, property damage and financial loss and in principle covers all damage arising out of the pollution of waterbodies, whether or not the event was sudden or accidental. The trigger of the cover was the point in time at which the pollutants entered the ground. In 1972 cover was extended to include the costs of cleaning up the ground of the insured's own property. What made sense for a heating-oil tank in the cellar of a private household caused considerable problems with industrial policyholders.

In 1988 many companies began restricting the WHG cover to malfunctions or interruptions in operation by incorporating an exclusion clause in the policy wording. This clause excluded cover for damage arising out of any events recurring over a period of time, events, e.g. spillage, dripping, evaporation, vaporisation. To complete the picture, I should add that since 1978 third party liability policies have also offered cover for impairment of the ground and air. Bodily injury and property damage caused gradually, but resulting from a malfunction or interruption in operation, are covered.

\subsection{The Environmental Impairment Liability (UHV) model}

The introduction of the UHG and with it the concept of liability arising out of normal operation prompted the HUK-Verband (Association of Casualty Insurers) together with all those involved in the market to devise a new insurance model. As far as cover for liability under the new Act is concerned, the UHV model reaches the limits of what is feasible. At the same time it is designed to replace the existing environmental impairment cover.

The basis for the UHV model is given by the incorporation of a new clause (Article 4.1.8) in the AHB which excludes damage arising out of environmental impacts from the existing third party liability cover. Insurers have simultaneously issued a statement to the effect that this exclusion will not apply to policies with private customers or in the product liability sector.

The environmental liability is insured via different covers, depending on whether the policyholder operates facilities which, according to the laws governing environmental protection, must be either licensed or reported.

In the absence of facilities of this kind the customer is granted the so-called Basic Cover. This cover is similar to what was previously insured under the third party liability policy but without the WHG cover.

If the insured operates facilities as listed in Appendices 1 and 2 UHG they are covered by means of optional modules. The insured is obliged to inform the insurer of all such facilities which he operates. The following cover modules are listed under Point 2 of the policy:

a) covers storage facilities in accordance with Article $20 \mathrm{WHG}$, provided they do not fall under the UHG owing to their size or the dangerousness of the stored substances;

b) covers facilities listed in Appendix 1 to the UHG; 
c) covers all facilities which, according to the laws governing environmental protection, must be either licensed or reported. Insofar as these facilities are not subject to the UHG, liability for them is restricted to that detailed in the Civil Code or the Federal Immission Prevention Act respectively;

d) covers waste-water facilities;

e) covers the facilities listed in Appendix 2 to the UHG.

For these facilities Article 12 of the Act prescribes compulsory liability cover. Until such time as the provisions of the compulsory insurance in accordance with $\$ 19$ UHG have come into force, these facilities are to be treated in the same way as those listed in Appendix 1 to the UHG;

f) covers planning, manufacture, delivery, assembly, dismantling, upkeep or maintenance of the facilities described under points 2.1 to 2.5 .

This is a special kind of product liability cover. It applies to damage due to environmental impairment for which the operator of a facility is held responsible. Having carried out work on the facility in question, the policyholder is in turn held liable by the operator by way of recourse;

g) adds the Basic Cover to the cover for facilities.

In individual cases this can also be provided separately.

What are the most important changes in cover offered by the new model over existing cover?

a) The new UHV model is a uniform system of cover for all damage due to environmental impairment of the ground, air or water.

b) Full cover is provided for the policyholder's legal liability under private law for damage due to environmental impairment. Not only are bodily injury and property damage insured, but also special forms of financial loss under German law, e.g. rights of appropriation. Such financial loss is treated as property damage. No cover is granted for general financial loss such as under Article 22 WHG.

By contrast, the UHV model intentionally does not distinguish between sudden and accidental and gradual damage.

c) The various definitions of the loss occurrence are replaced by a single definition. The loss occurrence is now defined as the first discovery of bodily injury or property damage due environmental impairment, regardless of both the extent or nature of that impairment and the possibility of estimating the size of the loss at that time.

d) The modules should cover only those facilities of which the policyholder notifies the insurer in writing. Facilities which have not been declared are not covered. Facilities which come in operation for the first time during the policy period must be agreed by the insurer.

e) Loss-prevention costs (i.e. costs incurred before occurrence of the insured event) are also covered, provided they were necessary to avert or reduce the extent of any loss covered by the policy. The policy contains a sublimit for such loss-prevention costs, which may also be triggered by an official order to eliminate ground pollution. Costs incurred for cleaning up the policyholder's own property are excluded. 


\section{f) Exclusions}

As already mentioned, the UHV model also covers damage caused gradually during normal operation. The cover for ground and water is restricted to that already provided under the amended WHG policy.

Thus the UHV model excludes damage due to spillage, draining off, dripping, evaporation or vaporisation of substances dangerous to water.

A further exclusion was incorporated in the cover which in fact contains an extension of cover. The first paragraph of Article 6.2 excludes damage accepted as unavoidable for the operation of a facility. What this means is that, as a rule, damage caused during the normal and approved operation of a facility is not covered.

However, paragraph 2 of this clause states that damage of this kind is in fact covered if the policyholder can prove that at the time of the impairment he did not know or could not have known that the facility was causing pollution.

It is usually quite easy for the policyholder to prove this by arguing that he would not have been granted an official licence to operate the facility had the danger posed by that facility been known.

Unfortunately the UHV model does not explicitly exclude environmental impairment already present when the policy was taken out.

Loss occurrences prior to commencement of the policy are excluded, as are those covered by earlier policies or for which the policyholder could have purchased cover previously. But all the cases described under points 6.3 to 6.5 of the UHV model, together with the new definition of the loss occurrence, mean that there is no effective exclusion of existing pollution.

The fact that cover is now triggered by the first discovery of bodily injury or property damage means that, although $90 \%$ of the damage potential may already have accumulated around the insured facility prior to commencement of the policy and only the remaining $10 \%$ of contributing emissions occur during the policy term, the insurer is liable for $100 \%$ of the ensuing damage. Although the trigger is thus closer to the present, the problem of longtail risks is by no means solved. Since there may be a period of time between the actual occurrence of the damage and discovery thereof, the policy provides for an extended reporting period of three years.

\section{Limits to the insurability of environmental impairment}

\subsection{Insurance conditions}

Moving away from the particular situation in Germany, I would now like to comment on the insurability of environmental impairment within the framework of traditional risktransfer agreements.

I think we all agree that third-party claims for damages for environmental impairment resulting from sudden and accidental events during operation of a policyholder's facility (e.g. explosion, fire) are not contradictory to the spirit of General Liability insurance.

Whether such risks can be insured within an third party liability policy or a separate policy according to traditional liability criteria or whether such insurance should be contingent upon a prior thorough survey and assessment of the business in question, depends both on the legal requirements and on the attitude of the individual insurer. 
However, the situation must be different for claims for damages in which the environmental impairment is due to production processes for which the policyholder has been granted an official licence or which arose as a result of ongoing carelessness.

This also applies to that portion of the impairment already present before commencement of the policy. Damage of this kind - often generally termed "gradual pollution" - cannot entirely be covered by traditional risk-transfer agreements. The biggest problem in this regard is the fact that the potential pollution builds up over many years before the loss occurs and that this potential is subject to changing - and usually stricter - liability.

Inclusion of such losses in traditional insurance agreements would require restricting or excluding the following loss occurrences:

\section{- Extended occurrences}

What we mean by this is the initial happening of one and the same process or activity over a long period of time which leads to the loss occurrence. This definition mainly concerns such processes/activities as spillage, dripping, draining off, evaporation and vaporisation.

- Foreseeable loss occurrences

Many production processes impact the environment. The assessment of whether such impacts are acceptable in the interests of the public must necessarily be carried out independently of insurance. Only those risks which cannot reasonably be foreseen should be the subject matter of insurance.

- Environmental impairment caused before commencement of the insurance

Environmental impairment caused before commencement of the insurance, which through later accrual finally leads to the loss occurrence, must be excluded from cover, along with any previous loss occurrences.

An environmental survey to assess the degree of existing pollution might complement or replace such an exclusion.

\subsection{Environmental protection requirements}

It is increasingly being discussed whether regular environmental audits actually simplify the insurance of environmental-impact risks. Basically it can be said that these environmental audits probably do more to help avoid malfunction and interruptions in operation than to reduce risk during normal operation.

\section{Reinsurers' reactions to the German UHV model}

\subsection{Problems for reinsurers}

Under the existing forms of XL cover, reinsurers had few problems with environmental risks. Only very few of the claims due to existing pollution were above the excess point. As a rule, an accumulation of these claims was impossible since, even in the case of several polluters, the occurrence definition determined a separate date of loss for each polluter.

Given the cover for normal operation, we see the loophole in Article 6.2 Paragraph 2 of the conditions as providing the first possibility within gencral liability insurance of blanket accumulation from the environmental medium air. 
It is currently impossible to estimate what may happen in future owing to

- the later amendment of limits for the pollution of the ground with known substances or

- the occurrence of damage through the emission of substance whose dangerousness is not known now.

Should such cases lead to restrictions in the use of property, the amounts spent cleaning up the property in question are not loss-prevention costs but property damage covered by the policy.

As many facilities of a similar type produce similar emissions, it is quite possible that, if a given facility causes an environmental impairment, facilities of the same type will be expected to impair the environment, too. This is of particular relevance to bodily injury claims arising out of widespread allergies. We should also remember that, for example, damage caused by the electromagnetic fields (EMF) produced by high-frequency power lines is regarded as environmental impairment from normal operation.

\subsection{Action taken by reinsurers}

It must not be forgotten that reinsurers in Germany participated in devising the UHV model and that, despite some reservation, they support it.

To change the existing portfolio to the new UHV model, the reinsurers have incorporated conditions in their reinsurance treaties stating that, with effect from 1 January 1994 or 1995 respectively, any new and renewed business shall be reinsured solely on the basis of the UHV model.

In addition, only policies with an original limit for normal operation losses not exceeding DM 20 million are to be ceded under the reinsurance treaties. Beyond this DM 20-million limit, reinsurance cover shall be given only for losses arising out of malfunctions or interruptions in operation.

This cover for operational malfunction is also available for plants located outside Germany and covered by German treaties, though it is worth stressing again in this context that under the UHV model this cover goes somewhat further than the customary sudden-andaccidental cover. According to the 1978 environmental conditions under third party liability policies, cover for environmental liability is dependent upon whether the damage was caused by a malfunction in operation. If a sudden malfunction or interruption in operation leads to emissions over a long period, thus causing damage, such damage is covered.

A further point is that the reinsurers generally insisted (at least of all facilities listed in Appendices 1 and 2 to the UHG) on an appropriate risk survey of the facilities to be reinsured. Moreover, the trcaties usually demand that environmental risks be rated separately.

\section{Rating}

Parallel with the approval of the UHV model, the Association of Casualty Insurers also presented a set of recommended net tariffs. The problem with these was that despite the large number of cases of existing pollution, no statistical material was available for the new cover.

It was decided therefore, in line with the liability, to recommend an individual premium for each facility to be insured. It is clear from this that use of the tariff requires a very thorough assessment of the risk. 


\section{Risk assessment}

During the transition to the UHV model the anticipated difficulties arose. These were:

- the necessity of assessing each individual facility and inadequate capacity for such surveys;

— insufficient material such as questionnaire forms for risk assessment;

- refusal of some policyholders and brokers to change over to the UHV model.

The market thus split quite soon into two camps. The one group's priority was to introduce the new conditions as quickly as possible across the whole market, so these reinsurers adapted the treaties first and reserved the right to carry out surveys later.

The other group regarded the risk surveys as an essential prerequisite for the changeover.

Bayerische Rück was faced here with the question of how we could help our clients assess and rate their environmental risks via our risk management subsidiary AssTech.

From the very outset of the environmental liability model debate, we had tried to develop for our facultative underwriters an OC-based system for assessing environmental risks. This system was then expanded and enhanced to become a class-by-class assessment and rating model for environmental risks called UIS.

UIS's PC-based inquiry system by class of business allows the underwriter or the risk surveyor to evaluate almost completely a particular environmental risk and the corresponding facilities without the aid of a technician.

Systematic questions help the user to uncover all facts of relevance to the risk. Even complex problems can be assessed quickly and easily. UIS can also be put to good use during an in-depth discussion with the client since only those questions are posed which are relevant to the risks in question, giving the client the feeling that they are to the point.

The facilites are evaluated by type, i.e. power generation, manufacture and processing, storage, and waste disposal. Taking into account the specific characteristics of each type of business, an analysis of the location is carried out which probes all loss potentials in respect of the surroundings, previous history, existing pollution and natural perils.

The user can leave questions unanswered where no information is available. If, however, any of these unanswered questions are material to the risk assessment, they are listed again at the end of each session.

In the case of high-risk factors, warnings are automatically displayed or the user is advised to have a proper technical risk assessment carried out. The UIS system cannot replace an environmental survey, but it is an aid to determining whether a large-scale environmental audit is necessary or not.

For the facilities assessed in this way, UIS can immediately calculate net and gross rates based on the Association recommendations for limits of indemnity between DM 2 million and DM 20 million. The Association recommendation can be replaced at any time with an insurer's own set of tariffs.

After each individual case has been processed UIS generates:

- a log of all answers given;

- a rating log containing the rates the individual facilities within the modules of the UHV model; and 
- a facility log, which lists all assessed facilities within the modules in accordance with Article 2 of the model.

These logs, which can serve as a basis for the insurance, list not only positive but also negative answers.

Whenever the answers in UIS point to a problematical facility - such as those listed in Appendix 2 to the UHG - or to other factors which might aggravate the risk, the system advises the user to consult a technician for an on-site survey of the risk. Although such surveys can be carried out by an indenendent environmental surveyor, Bayerische Rück can also provide this service, either in its own name or via its risk management subsidiary, with the advantage for the insurer being the fact that our staff is well acquainted with the insurer's needs and interests.

For the time being, Bayerische Rück's environmental consultancy activities are mainly oriented towards the German market, but we can well imagine adapting our risk assessment services to the needs of foreign markets. It would be going too far to say, however, that we are taking concrete steps towards this. 